\title{
The Effect of Cross-Domain Social Support and Work-Family Conflicts
}

\author{
Siti Nurmayanti* \\ Faculty of Economics and Busines \\ University of Mataram \\ Mataram, Indonesia \\ mayaramli24@unram.ac.id
}

\author{
Dwi Putra Buana Sakti \\ Faculty of Economics and Busines \\ University of Mataram \\ Mataram, Indonesia
}

\author{
I Nyoman Nugraha AP \\ Faculty of Economics and Busines \\ University of Mataram \\ Mataram, Indonesia
}

\begin{abstract}
Married working women often experience disruption between work and family life which is called workfamily conflict. To reduce this then one of the proven ways to reduce the level of work-family conflicts is through social support. Social support is a form of attention, appreciation, and assistance provided by several parties, which can be sourced from work (professional) social support in the realm of work and family (personal) social support that is obtained from the family. This study aims to analyze the effect of cross-domain social support on work-family conflicts among female nurses who work in a provincial general hospital. The paradigm used in this research was a positivist paradigm with the quantitative method as the appropriate design to achieve the research objectives. Through this approach, the researchers distributed a structured questionnaire, aimed at obtaining data to be analyzed, to 200 nurse respondents at the provincial general hospital with predetermined criteria. Data were analyzed using Partial Least Measurement (PLS). The results showed that there is an insignificant effect of professional social support on family conflicts to work in hospital female nurses and there is an insignificant effect of personal social support on work conflicts to the family of hospital female nurses.
\end{abstract}

Keywords- professional social support, personal social support, work-to-family conflicts, family-to-work conflicts

\section{INTRODUCTION}

For most individuals, the two most dominant domains of life are work and family[1][2]. When work and family are out of balance, well-being and quality of life are affected, causing high levels of stress and reducing their effectiveness in the workplace [2]

Disruption between work and family life, called workfamily conflict, commonly happens especially to women [3]. A work-family conflict is a form of conflict between roles in which the role pressures of the work and family domains are not aligned with each other in several ways [4]. The role stresses of work and family can go together in two directions at once. This means that excessive role demands from the realm of work (such as long working hours, inflexible work schedules, etc.) can cause interference/disruption of work to the family. Likewise, excessive role demands from the family realm (such as child care duties, housekeeping, chores, etc.) can cause interference/disruption of the family to work. So it is said to have a two-way/bi-directional nature [5].[6]state that there are two directions of disruption, namely the work domain that interferes with family life (work-to-family conflicts) and the family domain that interferes with work-life (family-to-work conflicts).
Based on empirical studies, work-family conflicts harm individuals, families, and organizations [7]. This encourages the researchers to deeply examine the factors that can reduce the level of work-family conflict among workers. One way that has been proven to reduce the level of work-family conflict is through social support [8]. Social support is a form of attention, appreciation, and assistance provided by several parties[9]. Social support can come from work (professional), social support that is obtained from superiors/supervisors, mentors, coworkers, and other people in the realm of work; and family (personal) social support that is obtained from families such as husband/wife, children, parents/in-laws, and friends [10].

Previous researches have focused extensively on the role of social support in buffering work-family conflicts encountered by employees (e.g.,[11];[8];[12];[13]. Studies on social support have mostly focused on the similar domain effects of social support ([1]; [3]), namely the relationship between work social support and work-to-family conflict, and between family social support and family-to-work conflicts[14]. [7] stated that social support from work and family can play an important role in the work-family conflict process. However, it is unclear whether the source of social support should match the domain where the conflict originates or belongs to another domain [15]. Most studies only investigate the impact of one source of social support, most often a partner or supervisor. However, the analysis of the relationship between social support and work-family conflict is inconsistent[3].

Several studies have reported cross-domain relationships, namely work-domain social support affecting family-to-work conflicts and family-domain social support affecting work-tofamily conflicts, but the relationship is poor or insignificant (e.g.[16][13][17][18][19][20][21][22][23]. A meta-analysis study of social support and work-family conflicts by argues that subsequent researchers should focus on cross-domain effects when analyzing social support and work-family conflicts [1][24]. This means that further research needs to be aimed at seeing the cross-domain influence between work social support and family social support on work-to-family conflicts and family-to-work conflicts.

The subjects of this study focused on married female nurses who work at the provincial government-owned public hospital in Mataram City. Nurses are professionals whose roles cannot be excluded from all forms of hospital services. This role was chosen because the nurses' job requires the longest contact with patients [25]. As married working women, nurses play a dual role. The dual role played by 
female nurses who have a very vulnerable family can lead to family-work conflicts. So the nurses need both, work social support and family social support which helps them to reduce the risk of experiencing work-family conflicts.

Based on the description above, this research was focused on answering the research problem of whether professional social support affects family-work conflicts and whether personal social support affects work-family conflicts in female nurses.

\section{METHODS}

This research is explanatory in which it was intended to explain the symptoms caused by a research object and to examine the hypothesized relationship between variables. The target population of this research was female nurses who worked at the general hospital of West Nusa Tenggara province in Mataram, totaling 370 nurses. The population reached for this research were female nurses who worked at the general hospital in West Nusa Tenggara province who met the following criteria: (1) married; (2) living with a partner; (3) has at least 1 child.

The size of the samples that were determined in this research was 200 female nurses who met the specified criteria, greater than 30 and less than 500 are sufficient for use in all studies. The survey method was used to obtain data through structured questionnaires followed by interviews. Respondents were given 1 set of questionnaires consisting of 4 parts containing statements to measure work-family conflict variables, family-work conflict variables, professional social support variables, and personal social support variables. Female nurses surveyed mainly aged 25 to 40 years, had completed higher education $(60.5 \%)$ and worked less than 10 years $(48.0 \%)$.

The analysis technique in this research was descriptive analysis and inferential analysis using Partial Least Square (PLS) with SMART PLS software assistance.

The conceptual framework to be tested is shown in the following Fig. 1

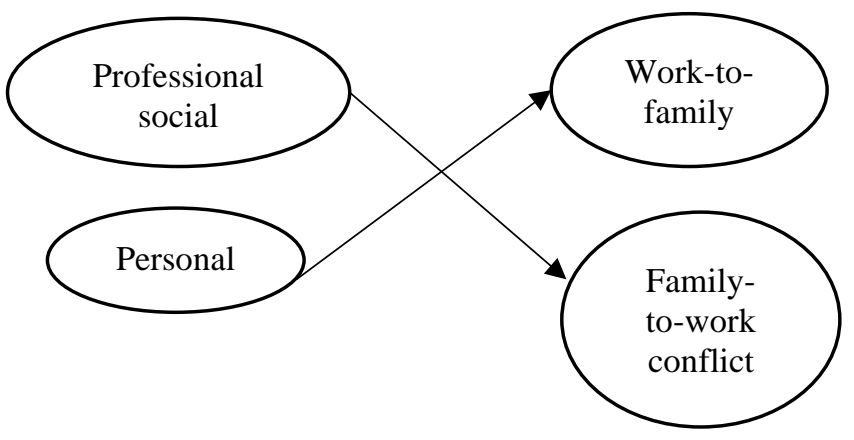

Fig. 1. Research conceptual framework

The research hypotheses proposed are:

1. Professional social support has a negative and significant effect on family-to-work conflicts

2. Personal social support has a negative and significant effect on work-to-family conflicts

\section{RESULTS AND DISCUSSION}

After the text edit has been completed, the paper is ready for the template. Duplicate the template file by using the Save As command, and use the naming convention prescribed by your conference for the name of your paper. In this newly created file, highlight all of the contents and import your prepared text file. You are now ready to style your paper; use the scroll down window on the left of the MS Word Formatting toolbar. The average rating for respondents' perceptions on personal social support (DP) variables is in the high category of 3.52 , meaning that the respondents receive social support from husband/child/parents at a high level. Extended family provides support as well for nurse respondents to carry out their work in the hospital. The mean value of respondents' perceptions for the professional social support variables is in the high category which equals to 3.50 . It means that respondents receive professional social support from their superiors, colleagues, and management at the hospital. High professional social support can make respondents feel comfortable in carrying out their duties. The average value of respondents' perceptions of family-to-work conflict (FIW) is low at 2.57. It means that the respondents experience family to work conflict in the low category. The variable of family-to-work conflict (FIW) has 3 indicators, namely family-to-work conflict based on time, based on strain, and based on behavior. The average value of respondents' perceptions of work-to-family conflicts (WIF) is low at 2.54. It means that the respondents experience workto-family conflicts in the low category. The work-to-family conflict (WIF) variable has 3 indicators, namely work-tofamily conflict based on time, based on strain, and based on behavior.

The results of PLS analysis include linearity assumption test, outer model (convergent validity, discriminant validity, and composite reliability), inner model (R-square analysis and causality test). The results of the linearity assumption test showed that the form of the relationship between variables in the structural model is linear $(\mathrm{P}<0.05)$ meaning that the linearity assumption in the model is met. The convergent validity results can be seen from the outer loading results. The results of the first round of outer loading showed that 3 items have outer loading smaller than 0.6 meaning that recalculation was carried out. After re-testing, the results of outer loading stage 2 contained 1 item that had an outer loading of less than 0.6 , so recalculation was carried out. The stage 3 test showed that outer loading is greater than 0.6 so that it could be used for the next analysis stage. The discriminant validity test was done by comparing the root of the AVE value for each variable with the correlation between the variable and other variables. The indicator is considered to meet the discriminant validity if the root of AVE is greater than the correlation among similar latent variables. Based on the results of the discriminant validity test, it shows that the AVE root of each variable is greater than 0.5 so that it can be stated that all variables are valid. Meanwhile, the result of the composite reliability of the two variables is reliable because the composite reliability is greater than 0.7 . The result of the inner model can be seen from looking at the R-square value, the predictive relevance value, and the causality test.

The $\mathrm{R}$ square value of the relationship between personal social support and professional social support variables on family-to-work conflicts (FIW) is 0.046. It shows that 4.6 
percent of the diversity of the family to work (FIW) conflict variable can be explained by the social support and professional social support variables, the remaining 95.4 percent is explained by other variables outside this research model. This R square value is classified as poor according to Chin (1998) in[26]. Meanwhile, the R-square value of the relationship between social personal support and professional social support variables on work-to-family (WIF) conflict is 0.051 . This means that 5.1 percent of the diversity of workto-family (WIF) conflict variable can be explained by the personal social support and professional social support variables, the remaining 94.9 percent is explained by other variables outside this research model. This R-square value is classified as poor according to Chin (1998) in[26]. The predictive relevance test obtained a Q-square value of 0.0946 . It indicates that the model has predictive relevance because it has a value greater than zero meaning that it is better and feasible to be used in prediction. The result of the causality test is explained in the following Table I:

TABLE I. RESEARCH HYPOTHESIS DECISION TABLE

\begin{tabular}{cccccccc}
\hline $\begin{array}{c}\text { Inter-Variable } \\
\text { Relationship }\end{array}$ & Hypothesis & $\begin{array}{c}\text { Original } \\
\text { Sample }\end{array}$ & t-statistic & $\begin{array}{c}\text { t- } \\
\text { table }\end{array}$ & $\begin{array}{c}\text { P- } \\
\text { value }\end{array}$ & Remark \\
\hline PROFS $\rightarrow$ FIW & 1 & -0.259 & 1.253 & 1.96 & 0.211 & $\begin{array}{c}\text { Insignificant } \\
\text { Decision }\end{array}$ \\
PS $\rightarrow$ WIF & 2 & -0.276 & 1.385 & 1.96 & 0.167 & $\begin{array}{c}\text { Suppothesignificant Not } \\
\text { Hypothesis Not } \\
\text { Supported }\end{array}$ \\
\hline
\end{tabular}

The results showed that there was an insignificant effect of professional social support on family-to-work conflict and there was an insignificant effect of personal social support on the work-to-family conflict in hospital nurses. It means that professional support from superiors, coworkers, and management and personal social support from families such as spouses, children, parents, and friends do not affect familyto-work conflict and work-to-family conflict of the hospital nurses.

Previous studies related to social support have always focused on the same domain effects of social support namely the relationship between professional social support and work to family conflict and between personal social support and family to work conflict[1];[3]: [24]. Social support from work and family can play an important role in the process of workto-family conflict. Social support can be seen as a social resource that is directly linked to family-work conflicts. The specific effect of the social support domain is highly strong, namely spouse support reduces family-to-work conflict, and support from superiors or coworkers reduces work-to-family conflict[3].

Several previous studies have found that family support can influence work-family conflicts. Previous studies have also shown that family support function can improve workto-family conflicts. Research conducted by several person shows that if the spouse (husband) provides greater support in terms of work and child care, work-to-family conflicts will not be a big problem for working women. Researcher found that higher family support tended to face a lower work-family conflict. Likewise, research by (Carlson \& Perrewe, The Role of Social Support In The Stressor-Strain Relationship: An Examination Of Work-Family Conflict, 1999)found that family support was negatively related to work-family conflicts.

The results of this research support several studies previously conducted that report a poor and insignificant cross-domain relationship between professional (work) social support on family-to-work conflicts and personal (family) social support on work-to-family conflicts (e.g.. $[20][16][1][3][21][22][23][18][17][2][19]$.
The high level of social support from the organization is unable to reduce the level of conflict originating from the family which will interfere with work. Problems that arise in the family as a result of the dual roles played by individuals will still trigger an imbalance so that it continues to create conflicts from the realm of the family to the realm of work. Social support from superiors/supervisors is unable to balance the role demands of the family domain which, in turn, affects the work domain. Likewise, high social support from the family cannot reduce the level of conflict originating from work which then disrupts family life. High workload, high work standards, overtime work, all of which can be a source of tension in the realm of work that will enter the family realm. Even though individuals have received high social support from spouses, parents, or children; it is still work-related disturbances that will enter the realm of the family.

This study found that cross-domain of professional (work) social support and personal (family) social support did not affect work-to-family conflicts and family-to-work conflicts. This finding supports the findings of previous studies which found that the cross-domain effect of professional social support and personal social support on work-to-family conflicts and family-to-work conflicts was poor and insignificant. For example researches from $[20][16][1][3][21][22][23][18][17][2][19]$.

\section{CONCLUSION}

In general, professional social support and family social support on hospital nurses are in a high category. Likewise, work-to-family conflicts and family-to-work conflicts experienced by hospital nurses are in a low category. Based on the test results, it was found that professional social support does not affect family-to-work conflicts and personal social support does not affect work-to-family conflicts. It means that professional social support that comes from superiors and co-workers, as well as personal social support from spouses, parents, or children, do not affect the level of family-to-work conflict and the level of work-to-family conflict. It is expected that the next research will re-examine this concept but by including the mediating variable between 
professional/personal social support on family-work conflicts / work-family conflicts.

\section{REFERENCE}

[1] J. S. Michel, L. M. Kotrba, J. K. Mitchelson, M. A. Clark, and B. B. Baltes, "Antecedents of Work-Family Conflict: A Meta-Analytic Review," J. Organ. Behav., vol. 32, pp. 689-725, 2011.

[2] C. -y. L. and K. -s. Hong, "Work-Family Conflict and Its Relationship With Social Support: A Study at Private Education a Institutions in Kuching, Sarawak," Malaysia Educ. Res. J., vol. 20, no. 2, 2005.

[3] C. P. S. and B. S. Wiese, "Social Support From Work and Family Domains as an Antecedent or Moderator of Work-Family Conflicts?," J. Vocat. Behavio, vol. 75, pp. 26-37, 2009.

[4] J. G. and N. J. Beutell, "Sources of Conflict Between Work and Family Roles,” Acad. Manag. Rev., vol. 10, pp. 76-88, 1985.

[5] D. S. Carlson, K. M. Kacmar, and J. Larry, "Construction And Validation of A Multidimensional Measure of Work-Family Conflict," J. Vocat. Behav., vol. 56, pp. 249-276, 2000.

[6] M. R. and M. C. M. Frone, "Antecedents and Outcomes of Workfamily conflict Testing a Model of the Work-Family Interface," J. Appl. Psychol., vol. 77, no. 1, pp. 65-78, 1992.

[7] L. T. Eby, W. J. Casper, A. Lockwood, C. Bordeaux, and A. Brinley, "work and family research in IO/OB: Content analysis and review of the literature (1980-2002)," J. Vocat. Behav., vol. 66, pp. 124-197, 2005

[8] D. S. C. and P. L. Perrewe, "The Role of Social Support In The Stressor-Strain Relationship: An Examination Of Work-Family Conflict,”J. Intern. Manag., vol. 25, no. 513, 1999.

[9] E. Sarafino and T. W. Smith, Health Psychology: Biophysical Interactions. Toronto: John Wiley \& Sons, 2010.

[10] S. R. Ezzedeen and K. G. Ritchey, Career Advancement and Family Balance Strategies of Executive Women. Gender in Management, 2009

[11] T. D. Allen, "Family-supportive Work Environments: The Role of Organizational Perceptions," J. Vocat. Behav., vol. 58, no. 3, pp. 414435, 2001.

[12] A. A. G. and R. Cropanzano, "The Conservation of Resources Model Applied to Work-Family Conflict and Strain,” J. Vocat. Behav., vol. 54, pp. 350-370, 1999.

[13] J. S. Michel, J. K. Mitchelson, S. Pichler and K. L. Cullen, "Clarifying Relationships Among Work And Family Social Support, Stressors, and Work-Family Conflict," J. Vocat. Behav., vol. 76, pp. 91-104, 2010.

[14] P. A. C. and B. S. T. Selvarajan, "Social Support and Work-Family Conflict: A Test of an Indirect Effects Model," J. Vocat. Behav., vol. 83, pp. 486-499, 2013.

[15] C. N. and K. Sonntag, "Work-Family Conflict, Social Support, and Turnover Intentions: A Longitudinal Study,” J. Vocat. Behav., 2014.

[16] M. S. DiRenzo, J. H. Greenhaus, and C. H. Weer, "Job Level, Demands, and Resources as Antecedents of Work-Family Conflict," J. Vocat. Behav., vol. 78, no. 2, pp. 305-314, 2011.

[17] N. H. and S. L. S. Foley, "The Effects of Work Stressors, Perceived Organizational Support, and Gender on Work-Family Conflict in Hong Kong,” Asia Pacific J. Manag., vol. 22, No. 3, pp. 237-256, 2005.

[18] J. R. M.-M. and C. Visweswaran, "Convergence Between Measures Of Work-to-Family and Family-to-Work Conflict: A Meta-Analytic Examination,”J. Vocat. Behav., vol. 67, pp. 215-232, 2005.

[19] N. F. and J. Breaugh, "Family-Friendly Policies, Supervisor Support, Work-Family Conflict, and Satisfaction: A Tes of a Conceptual Model,” J. Bus. Psychol., vol. 77, no. 1, pp. 197-220, 2004.

[20] L. A. M. and S. Pichler, "A Comparison of Types of Support for Lower-Skill Workers: Evidence for the Importance of Family Supportive Supervisors," J. Vocat. Behav., vol. 79, no. 3, pp. 653-666, 2011.

[21] K. S. and T. Allen, "When Flexibility Helps: Another Look At The Availability of Flexible Work Arrangements and Work-Family Conflict,”J. Vocat. Behav., vol. 7, no. 3, pp. 479-493, 2007.
[22] T. W. and K. S. V. G. Daalen, "Reducing Work-Family Conflict Through Different Sources of Social Support," J. Vocat. Behav., vol. 69, no. 3, pp. 462-476, 2006.

[23] L. W. and D. S. Carlson, "The Work-Family Interface and Job Performance: Moderating Effects of Conscientiousness and Perceived Organizational Support,” J. Occup. Heal. Psychol., vol. 11, no. 4, pp. 343-357, 2006.

[24] P. A. C. and B. S. T. Selvarajan, "Social Support and Work-Family Conflict: A Test of an Indirect Effects Model," J. Vocat. Behav., vol. 83, pp. 486-499, 2013.

[25] A. Murtiningrum, "Analysis of the Effect of Family-work conflict on Work Stress with Social Support as a Moderation Variable (Case Study of Class 3 Teachers of State Junior High Schools in Kendal Regency)," Semarang: Diponegoro University, 2005.

[26] I. G. and H. Latan, "Concepts, Techniques, Applications Using Smart PLS 3.0 for Empirical Research,” Semarang: BP Undip, 2015. 